

\section{Sumário}

A DISCRIMINAÇÃo RACIAL NO BRASIL E A ASCENSÃo DO POVO NEGRO: UM OLHAR A PARTIR DOS PRINCÍPIOS CONSTITUCIONAIS NA LUTA PELA CIDADANIA INCLUSIVA

Bruno Mello Correa de Barros e Rita Mara Albrecht

As MULHERES NO CONTEXTO DA SOCIEDADE DE CLASSES E SUA PARTICIPAÇÃO POLÍTICA NO PROCESSO LEGISLATIVO E EXECUTIVO DO BRASIL: RESTRIÇÕES E DESAFIOS

Rafael Bueno da Rosa Moreira e Marli Marlene Morais da Costa

FACTORES ASOCIADOS A LA VIOLENCIA DE GÉNERo EN PAREJAS ADOLESCENTES

Maria del Carmen Monreal Gimeno

Os IMPACTOS DAS TECNOLOGIAS DA INFORMAÇÃO NO FLUXO DE PESSOAS: VIOLAÇÕES DA LIBERDADE EM UM MUNDO SECURITIZADO

Elias Jacob de Menezes Neto, Jose Luis Bolzan de Morais e Victoria Layze Silva Fausto

El DELITO DE ENALTECIMIENTO TERRORISTA. ¿INSTRUMENTO DE LUCHA CONTRA EL PELIGROSO DISCURSO DEL ODIO TERRORISTA O MECANISMO REPRESOR DE REPUDIABLES MENSAJES DE RAPEROS, TWITTEROS Y TITIRITEROS?

Alfonso Galán Muñoz

As POLÍtiCAS PÚBLICAS E A PROMOÇão DA DIGNIDADE: UMA ABORDAGEM NORTEADA PELAS CApacidades (CAPABIlities APproach) propostas por Martha Nussbaum

Anna Paula Bagetti Zeifert e Janaína Machado Sturza

A INFLUÊNCIA DA MÍdia PARA O CONSUMO DE TABACO

Luís Renato Vedovato e Maria Carolina Gervásio Angelini

¿SON PARTE DEL BLOQUE DE CONSTITUCIONALIDAD LOS PRINCIPALES TRATADOS internacionales de derechos humanos de la ONU en Chile? Del texto positivo a la APLICACIÓN EN TRIBUNALES DE JUSTICIA Juan Pablo Díaz Fuenzalida

Potestad calificadora del Conservador de Bienes Raíces y Procedimiento Registral ....173 Sebastián Bozzo Hauri e Gonzalo Ruz Lartiga

DESARTICULAÇÃo INTERFEDERATIVA E CONCESSÃo DOS BENEFÍCIOS DE PRESTAÇÃo CONTINUADA (BPC) 
Aprendizagem Profissional e o poder público municipal: proposta de maior eficácia À POLÍTICA PÚBLICA

José Rodrigo Paprotzki Veloso

Direito A Conciliação Entre Trabalho E Família................................................229

Edilton Meireles de Oliveira Santos

Trabajo y diversidad funcional. La situación EN EL ORdenamiento JuRídico español 245 María Esther Carrizosa Prieto

Custos de TransaÇão como uma METAPolítica pública .........................................2276

João Luis Nogueira Matias e Ricardo José Brito Bastos Aguiar de Arruda

REVISITANDO O CONCEITO DE SERVIÇO PÚBLICO

Andre Luiz Dos Santos Nakamura

O Brasil FACE AOS NOVOS PADRÕES DE COMÉRCIO E INVESTIMENTO DOS ACORDOS INTERNACIONAIS

Michelle Sanchez Badin, Fabio Costa Morosini e David M. Trubek

Os contratos comerciais na Declaração dos Direitos de Liberdade Econômica (MP 881/19).

André Lipp Pinto Basto Lupi

O MARCO LEGAL DA INOVAÇÃO E O AUMENTO DA INTERAÇÃO ENTRE UNIVERSIDADE E EMPRESA: CONTRIBUIÇÕES PARA A CONSOLIDAÇÃO DO DIREITO FUNDAMENTAL AO DESENVOLVIMENTO ....352 Thiago Paluma e Eline Débora Teixeira

RELICITAÇÃo DAS CONCESSÕES DE GERAÇÃo DE ENERGIA ELÉTRICA E A REVERSÃo DE BENS....372 Patrícia Regina Pinheiro Sampaio e Sergio Guerra

FinANCIAMENTO TRANSGERACIONAL DA INFRAESTRUTURA VERDE FLORESTAL: O SISTEMA DE PAGAMENTO POR SERVIÇOS AMBIENTAIS COMO INSTRUMENTO DE GESTÃO DE RISCOS NA SOCIEDADE CONTEMPORÂNEA...................................................................................................390

Délton Winter de Carvalho e Kelly de Souza Barbosa

Mediação como Política Pública para Tratamento de Conflitos Consumeristas ..... 415 Fernanda Sartor Meinero e Fernando Pedro Meinero

A ParticipaÇão do AMICUS CURIAE EM DECISÕES JUdiCIAIS E SUA CONSEQUENTE CONTRIBUiÇÃo para efetivação de Políticas Públicas .429

Viviane Nobre Santana 
A ISONOMIA TRIBUTÁRIA COMO LIMITE À TRIBUTAÇÃo E À CONCESSÃO DE ISENÇÕES FISCAIS, E A INEFETIVIDADE DO CONTROLE JURISDICIONAL DESSAS ISENÇÕES..................................450

Paulo Alves da Silva Paiva e Alexandre Augusto Batista de Lima


ET JUSTICE AMIABLE

Marie-Odile Diemer

O ESTADO DA LUXÚRIA: A PARÁBOLA DO BMW E A REAL DIMENSÃo DO DEBATE SOBRE A RESERVA DO POSSÍVEL: ESCASSEZ DE RECURSOS OU ORDENAÇÃo DE PRIORIDADES?................................484 Assis José Couto do Nascimento

O PODER CONSTITUINTE

José Levi Mello do Amaral Júnior

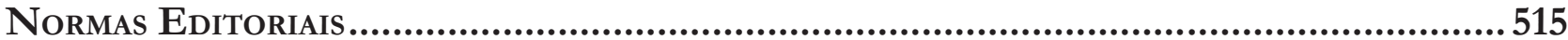

Envio dos trabalhos: 


\title{
Revisitando o conceito de serviço público*
}

\section{Revisiting the concept of public utility}

\author{
Andre Luiz Dos Santos Nakamura**
}

\section{Resumo}

Este artigo tem por objetivo revisitar e atualizar o conceito de um instituto fundamental ao estudo do Direito Administrativo: o serviço público. A metodologia utilizada é a hipotético-dedutiva; por meio de pesquisas bibliográficas, serão analisados os conceitos de serviço público que serão refutados ou confirmados, tendo em vista o Direito Positivo brasileiro. Concluímos que o conceito de serviço público não é mais o da Escola Francesa, bem como que os institutos do Direito Europeu e Estadunidense de "serviços econômicos de interesse geral" e "public utilities" não são totalmente adequados ao conceito de serviço público positivado na Constituição Federal; conclui-se que o conceito de serviço público deve ser visto como uma atividade econômica que foi, por meio de lei, atribuída ao Estado para que a exerça de forma direta ou por meio de concessão ou permissão, sempre tendo em vista a finalidade de dar efetividade aos direitos fundamentais.

Palavras-chave: Serviço público. Atividade econômica. Direitos sociais.

\section{Abstract}

This article aims to revisit and update the concept of a fundamental institute for the study of Administrative Law: the public utility. The methodology used is hypothetico-deductive; by study of bibliographical researches, the concepts of public utility will be analyzed, which will be refuted or confirmed, in view of Brazilian Positive Law. We conclude that the concept of public utility is no longer that of the French School, as well as that the institutes of European and American law of "economic services of general interest" and "public utilities" are not totally adequate to the concept of public utility disciplined in the Federal Constitution; it is concluded that the concept of public utility should be seen as an economic activity that was, by means of law, attributed to the State to exercise it directly or through concession or permission, always with a view to giving fundamental rights.

Keywords: Public utility. Economic activity. Social rights.

** Procurador do Estado de São Paulo. Doutor em Direito e Bacharel em Direito pela Universidade Presbiteriana Mackenzie. Mestre em Direito pela Pontifícia Universidade Católica de São Paulo (PUC/SP). Especialista em Direito Processual Civil pela Escola Superior da Procuradoria do Estado de São Paulo. Professor e monitor do Curso de Especialização em Direito do Estado na Escola Superior da Procuradoria do Estado de São Paulo. Professor nas disciplinas de Direito do Estado na Universidade Paulista (UNIP). Email: alsnadv@gmail.com

* Recebido em 27/07/2017 Aprovado em 29/08/2017 


\section{Introdução}

O conceito de serviço público é marcado por divergências que devem, ainda, devem ser enfrentadas. As divergências doutrinárias ainda reinam acerca do assunto. Entretanto, trata-se de assunto de vital importância ao Direito Administrativo e ao Direito Público.

Revisitamos os conceitos da doutrina tradicional, a Escola Francesa do serviço público, bem como as tendências atuais acerca do serviço público na Europa e nos Estados Unidos, para atualizarmos o conceito de serviço público, de acordo com o Direito Positivo brasileiro.

Também, enfrentamos a controvérsia sobre a distinção entre serviço público e atividade econômica, bem como a natureza jurídica dos serviços de saúde e educação.

\section{Serviço público e atividade econômica}

A Constituição Federal, em seu Título VII, disciplinou a ordem econômica e financeira. A atuação do Estado na econômica, conforme decorre da disciplina Constitucional, se dá de três formas: i) na forma de exploração direta de atividade econômica ${ }^{1}$; ii) como prestador de serviço público ${ }^{2}$; iii) como agente normativo e regulador da atividade econômica ${ }^{3}$.

Cabe, primeiramente, diferenciar serviço público e atividade econômica. Não há uma diferença substancial entre serviço público e atividade econômica. Esta compreende aquele ${ }^{4}$. Conforme lição de Eros Grau ${ }^{5}$, "a prestação de serviço público está voltada à satisfação de necessidades, o que envolve a utilização de bens e serviços, recursos escassos...o serviço público é um tipo de atividade econômica”. A atividade econômica prestada pelo Estado visando à satisfação de interesses da sociedade, desde que submetida por lei a um regime jurídico diferenciado, é o serviço público.

Diferentemente da atividade econômica realizada pelos privados, o serviço público não necessariamente busca o lucro. O serviço público pode ser deficitário, desde que atenda aos interesses da coletividade. Se o atendimento do interesse público der prejuízo, o serviço público deverá ser custeado, de forma deficitária, pelo Estado ${ }^{6}$.

Dessa forma, o serviço público é uma atividade econômica. A princípio, o que diferenciaria a atividade econômica em sentido estrito do serviço público seria a possibilidade de participação do particular. Se o

\footnotetext{
1 Art. 173. Ressalvados os casos previstos nesta Constituição, a exploração direta de atividade econômica pelo Estado só será permitida quando necessária aos imperativos da segurança nacional ou a relevante interesse coletivo, conforme definidos em lei.

2 Art. 175. Incumbe ao Poder Público, na forma da lei, diretamente ou sob regime de concessão ou permissão, sempre através de licitação, a prestação de serviços públicos.

3 Art. 174. Como agente normativo e regulador da atividade econômica, o Estado exercerá, na forma da lei, as funções de fiscalização, incentivo e planejamento, sendo este determinante para o setor público e indicativo para o setor privado.

4 Sobre as atuais dificuldades em separar os conceitos de serviço público e atividade econômica, "A clássica apartação entre serviço público, de um lado, sujeito ao regime jurídico único e absolutamente diferente do regime privado, e a noção de atividade econômica, de outro, com regime de liberdade plena e totalmente alheio à regulação estatal, não é a mais suficiente para explicar a dicotomia ou mesmo para justificá-la. Em muitos serviços, hoje em dia, ocorre uma assimetria de regimes, como é o caso do serviço de transporte intermunicipal de passageiros em concorrência com os fretamentos, sob regimes jurídicos distintos". MARQUES NETO, Floriano de Azevedo. Evolução do Serviço Público. In: KLEIN, Aline Lícia; MARQUES NETO, Floriano de Azevedo. Tratado de Direito Administrativo: funções administrativas do Estado. Coordenação: Maria Sylvia Zanella Di Pietro. São Paulo: Revista dos Tribunais, 2014. p. 31-87. v. 4.

5 GRAU, Eros. A ordem econômica na Constituição de 1988. 17. ed. São Paulo: Malheiros, 2015. p. 100.

6 Nesse sentido: "O serviço público, contrariamente à empresa privada, pode muito bem funcionar com prejuízo. Esta é mesmo uma das suas razões de ser: incumbe-lhe satisfazer as necessidades cuja não-rentabilidade afasta a empresa privada. Só a pessoa pública, por meio do imposto, pode transferir dos utentes para o conjunto das colectividades o financiamento do serviço”. RIVERO, Jean. Direito administrativo. Tradução Rogério Ehrhardt Soares. Coimbra: Almedina, 1981. p. 494.
} 
mercado pudesse realizar a atividade econômica por conta própria, atendendo plenamente aos interesses dos usuários, sem necessidade de qualquer interferência estatal, não ocorreria a hipótese de serviço público. Nos casos em que o mercado não tivesse interesse em realizar determinada atividade, ou a realizasse de uma forma que não atendesse ao interesse público, como por exemplo, mediante a cobrança de tarifas altas, estaríamos diante de um caso em que a presença estatal se faria necessária. Segundo Justen Filho:

Os serviços públicos se configuram nas situações de necessidades relevantes e essenciais, cujo atendimento não pode ser promovido satisfatoriamente mediante os mecanismos próprios da livreiniciativa privada. A prestação de serviço público faz-se sob regime distinto daquele previsto para a atividade econômica propriamente dita, não incide a livre-iniciativa, e os serviços são prestados sob os princípios da continuidade, da universalidade, da isonomia, da modicidade tarifária e outros similares.

Há quem entenda que o suposto desinteresse da iniciativa privada para realizar determinada atividade não a tornaria um serviço público. A previsão do art. 173 de que o Estado poderia desempenhar determinadas atividades econômicas, no caso de segurança nacional ou relevante interesse coletivo, não seria o fundamento do serviço público, visto que tal previsão trataria, apenas, das atividades econômicas a serem realizadas pelo Estado em concorrência com a iniciativa privada. Assim, o Estado não poderia, sob o pretexto de ocorrência de segurança nacional ou relevante interesse coletivo, transformar qualquer atividade econômica em serviço público ${ }^{8}$, conforme entendimento de Fernando Herren Aguillar?:

Não há, portanto, como se sustentar que atividades econômicas em sentido estrito seriam suscetíveis de transformar-se em serviços públicos quando atendessem a imperativos de segurança nacional ou a relevante interesse coletivo definidos em lei, com apoio no art. 173 da Constituição Federal.

Se adotada a premissa acima, somente seriam serviços públicos os que a Constituição tivesse atribuído, expressamente, ao Estado, retirando-os do âmbito de atuação dos particulares. Segundo Fernando Herren Aguilar ${ }^{10}$, "em nossa atual sistemática constitucional, os serviços públicos são aqueles contidos no corpo da Carta Política, o que só pode ser alterado por Emenda Constitucional”. Segundo tal entendimento, se determinada atividade não estivesse já prevista pela Constituição como de atribuição do Estado, ela somente poderia ser transformada em serviço público mediante emenda constitucional ${ }^{11}$.

Segundo Luiz Gustavo Kaercher Loureiro, a noção de serviço público deveria ser extraída da exegese conjunta dos arts. 173 e 175 da Constituição Federal. O art. 173 reza que "ressalvados os casos previstos nesta Constituição, a exploração direta de atividade econômica pelo Estado só será permitida quando necessária aos imperativos da segurança nacional ou a relevante interesse coletivo, conforme definidos em lei”. Os serviços públicos seriam os "casos previstos" que a Constituição reservou ao Estado, retirando-as da iniciativa privada:

A segregação a ser feita, à luz apenas do art. 173, aparta as atividades econômicas imputadas ao Estado pela Constituição ("ressalvados os casos previstos nesta Constituição") e o restante do universo econômico, em princípio entregue à livre iniciativa e onde o Estado só poderá atuar quando legitimado por lei ("a exploração direta de atividade econômica pelo Estado só será permitida quando necessária

\footnotetext{
JUSTEN FILHO, Marçal. Contornos da atividade administrativa de fomento no direito administrativo brasileiro: novas tendências. In: MELLO, Celso Antônio Bandeira de et al. Direito Administrativo e Liberdade: Estudos em homenagem a Lúcia Valle Figueiredo. São Paulo: Malheiros, 2014. p. 536-566.

8 Nesse sentido: "Algunos autores, entonces, optan por decir que será servicio público lo que el legislador diga que lo es. Ese razonamiento no es criticable per se, pero obliga a una aclaración: si el legislador aplica irrazonablemente un régimen legal como el del agua, a la electricidad, etc., la venta de ballenitas en la vía pública, esa ley será inconstutucional”. GORDILLO, Agustín. Tratado de Derecho Administrativo. 5. ed. Belo Horizonte: Del Rey e Fundación de Derecho Administrativo, 2003. Tomo 2. p. 6-7.

9 AGUILLAR, Fernando Herren. Direito Econômico: do Direito Nacional ao Direito Supranacional. São Paulo: Atlas, 2016. p. 346347.

10 Aguillar, Fernando Herren. Direito Econômico: do Direito Nacional ao Direito Supranacional. São Paulo: Atlas, 2016. p. 350.

11 Nesse sentido: "Assim, se não quisermos desconsiderar o art. 173, teremos que admitir, logicamente, que somente épossivel instituir serviços públicos não previstos constitucionalmente mediante emenda constitucional". AGUILLAR, Fernando Herren. Direito Econômico: do Direito Nacional ao Direito Supranacional. São Paulo: Atlas, 2016. p. 349.
} 
aos imperativos da segurança nacional ou a relevante interesse coletivo, conforme definido em lei") ${ }^{12}$.

Partindo-se da noção acima, dentre as atividades reservadas ao Estado, nem todas poderiam ser categorizadas como "serviço público". Este somente seria parte de um universo maior que abrangeria as atividades que a Constituição reservou ao Estado. Dentre estas, incluir-se-iam as chamadas competências públicas, ou seja, atividades que deveriam ser desempenhadas pelo Estado, mas que poderiam, também, ser desempenhadas pela iniciativa privada, tais como saúde e educação ${ }^{13}$. Dentre as atividades estatais que seriam vedadas à iniciativa privada, estariam os denominados monopólios estatais ${ }^{14}$, como os previstos no art. 177 da Constituição e, por fim, os serviços públicos. Estes se constituiriam nas atividades reservadas pela Constituição ao Estado que este deveria prestar pessoalmente ou por meio de delegação a particulares, mediante concessão ou permissão. Nesse sentido, Luiz Gustavo Kaercher Loureiro ${ }^{15}$ :

Serviço público é a atividade de produção e/ ou circulação de bens e serviços referentes a uma determinada área econômica, atribuída pela Constituição ao Poder Público, dotada, por opção do legislador ordinário, de um regime jurídico específico estampado no art. 175 - caracterizado fundamentalmente pela existência de uma "política tarifária", pela obrigação de um "serviço adequado" e pela responsabilidade civil objetiva -, cuja execução pode ser delegável a privados, por meio de específicos instrumentos que assegurem o pleno exercício da competência pública e o oferecimento do "serviço adequado" ao usuário.

Entretanto, data máxima vênia, não parece correto entender que todo o exercício de todo serviço público é vedado aos particulares, bem como que somente por emenda constitucional seria possível a criação de novos serviços públicos.

Conforme acima dito, a Constituição Federal, expressamente, em "serviços públicos de saúde", no art. 198 e no art. 199, estabelece que a iniciativa privada pode, livremente, exercer atividades na área da saúde. Tais dispositivos revelam que o conceito de serviço público não é restrito às atividades que somente podem ser prestadas pela iniciativa privada por meio de concessão e permissão. Assim, faz-se necessário buscar um conceito de serviço público que possa atender às peculiaridades do ordenamento constitucional brasileiro.

12 LOUREIRO, Luiz Gustavo Kaercher. Premissas para uma leitura integrada da indústria de energia na Constituição e para a identificação de uma política energética constitucional - a propósito dos arts. 173 e 175 da Carta. In: ARAGÃO, Alexandre Santos de. Direito do petróleo e de outras fontes de energia. Rio de Janeiro: Lumen Juris, 2011. p. 303-325.

13 Nesse sentido: "Se uma atividade puder ser desempenhada por particulares sem concessão ou permissão, ela não pode ser considerada serviço público...se saúde e educação fossem serviços públicos, não poderiam ser livremente desempenhados pela iniciativa privada, ou então o art. 175 da Constituição teria que ser tomado como letra morta, o que é inadmissível...não são serviços públicos em sentido estrito, mas funções do Estado". AGUILLAR, Fernando Herren. Direito Econômico: do Direito Nacional ao Direito Supranacional. São Paulo: Atlas, 2016. p. 355.

14 Anoto que há quem não diferencie monopólio e serviço público: “À classe de "monopólio" - ou "privilégio" -, foram, no passado, atribuídas as atividades que o Estado perseguia a título de lucro, realizadas com propósitos fiscais (daí a antiga expressão "monopólios fiscais", encontradiça na doutrina mais antiga), enquanto os "serviços públicos" eram identificados com as tarefas realizadas para efetivo atendimento de interesses que hodiernamente qualificar-se-iam de primários (atendimento a interesse coletivo, social, imperativos de segurança nacional, dentre outros)... atualmente, em face do presente texto constitucional e da convicção generalizada de que o Estado não mais se faz empresário para satisfazer interesses fiscais (interesses públicos secundários) a distinção não mais poderia ser feita nestas bases, uma vez que a Constituição, em seu art. 173, impositivamente, asseverou que qualquer ação econômica estatal há de atender a interesses públicos. Em outras palavras, não há espaços, na Constituição, para os monopólios fiscais... Em síntese, ao tomar a competência econômica pública prestacional como o conceito primitivo (de gênero), é possível e mesmo recomendável ultrapassar a distinção tradicional entre serviço público e atividade econômica monopolizada, como se as atividades enquadradas em uma e em outra categoria atendessem a objetivos diferentes e fossem (necessariamente) regidas por princípios e regras diferentes". LOUREIRO, Luiz Gustavo Kaercher. Premissas para uma leitura integrada da indústria de energia na Constituição e para a identificação de uma política energética constitucional - a propósito dos arts. 173 e 175 da Carta. In: ARAGÃO, Alexandre Santos de. Direito do petróleo e de outras fontes de energia. Rio de Janeiro: Lumen Juris, 2011. p. 303-325.

15 LOUREIRO, Luiz Gustavo Kaercher. Premissas para uma leitura integrada da indústria de energia na Constituição e para a identificação de uma política energética constitucional - a propósito dos arts. 173 e 175 da Carta. In: ARAGÃO, Alexandre Santos de. Direito do petróleo e de outras fontes de energia. Rio de Janeiro: Lumen Juris, 2011. p. 303-325. 


\section{Conceito de serviço público}

O conceito de serviço público é marcado pela divergência na doutrina e falta de precisão conceitual. Tal fato decorre da disciplina constitucional sobre o serviço público que utiliza o termo para se referir a situações totalmente distintas. No art. 175, a Constituição declara que os serviços públicos são prestados, diretamente, pelo Poder Público ou pelo particular, na forma da concessão e permissão; nota-se que a atividade privada nos referidos "serviços públicos" é vedada, salvo concessão ou permissão dada pelo Estado. Por outro lado, a Constituição, também, denomina expressamente como "serviço público" a saúde ${ }^{16}$ a qual pode ser livremente exercida pela iniciativa privada $^{17}$, o mesmo ocorrendo com a educação que, também, é uma atividade livre para ser exercida pela iniciativa privada $^{18}$.

A Constituição Federal disse que o serviço público é permitido à iniciativa privada somente por permissão ou concessão de serviço público e, posteriormente, expressamente, declarou que alguns dos serviços públicos (saúde e educação) são livres à iniciativa privada. Em relação aos exemplos expostos, percebe-se que cabe à doutrina definir o conceito de serviço público, em vista da ausência de critério normativo preciso na Constituição Federal, conforme alerta de Floriano de Azevedo Marques Neto ${ }^{19}$.

A própria Constituição não trata do termo serviço público com uma única acepção. Por isso é no mínimo muito difícil extrair do texto constitucional uma concepção única de serviço público, como procura fazer parte da doutrina do Direito administrativo brasileiro. Ainda que sejam úteis e até necessárias as interpretações do texto constitucional, a verdade é que o texto não favorece muito as apartações dicotômicas. Por isso não se pode afirmar que a noção de serviço público entre nós seja uma construção constitucional, mas sim doutrinária.

O direito brasileiro foi fortemente influenciado pela Escola Francesa do serviço público.

\subsection{A Escola Francesa do serviço público}

Segundo Duguit, o serviço público pode ser conceituado como toda atividade cuja realização deva ser assegurada, disciplinada e controlada pelos governantes, na medida em que a realização dessa atividade seja essencial e indispensável à efetivação e ao desenvolvimento da interdependência social, e não possa se realizar a não ser com a intervenção estatal. Diferentemente, "para Jèze não é a essencialidade que vai determinar se é ou não serviço público, e sim a opção política ${ }^{200}$. Segundo Gaston Jezééc:

En resumen, el servicio público es un procedimiento tecnico - y no el unico - con el que se satisfacen las necesidades de interés general. Decir que, em determinado caso, existe servicio público, significa que los agentes tienen la possibilidad de usar procedimientos del derecho público, de apelar a teorías y a reglas especiales, o sea, de recurrir a um régimen jurídico especial: este régimen se caracteriza por la subordinación de los intereses privados al interés general; la organización del servicio es siempre modificable con arreglo a las necesidades del interés general, $y$, em consecuencia, legal y regulamentaria.

O direito francês busca conceituar o serviço público por uma razão prática, qual seja, determinar o órgão responsável pelo eventual julgamento da relação jurídica. Se houver o serviço público, a competência é

\footnotetext{
16 Art. 198. As ações e serviços públicos de saúde integram uma rede regionalizada e hierarquizada e constituem um sistema único, organizado de acordo com as seguintes diretrizes:

17 Art. 199. A assistência à saúde é livre à iniciativa privada.

18 Art. 209. O ensino é livre à iniciativa privada...

19 MARQUES NETO, Floriano de Azevedo. Evolução do Serviço Público. In: KLEIN, Aline Lícia; MARQUES NETO, Floriano de Azevedo. Tratado de Direito Administrativo: funções administrativas do Estado. Coordenação: Maria Sylvia Zanella Di Pietro. São Paulo: Revista dos Tribunais, 2014. p. 89-113. v. 4.

20 MARQUES NETO, Floriano de Azevedo. Evolução do Serviço Público. In: KLEIN, Aline Lícia; MARQUES NETO, Floriano de Azevedo. Tratado de Direito Administrativo: funções administrativas do Estado. Coordenação: Maria Sylvia Zanella Di Pietro. São Paulo: Revista dos Tribunais, 2014. p. 31-87. v. 4.

21 JEZÉ, Gaston. Principios generales del Derecho Administrativo. Traducion por Julio N. San Millán Almagro. Buenos Aires: Depalma, 1949 . p. 18.
} 
do denominado Conselho de Estado, órgão contencioso administrativo; se não houver o serviço público, a competência para eventual julgamento seria do Poder Judiciário. Também, tinha por finalidade determinar a incidência do regime jurídico de direito público na relação jurídica. Nesse sentido é a lição de Agustín Gordillo ${ }^{22}$ :

La noción de servicio público nació y floreció em Francia caracterizada como actividad de determinado tipo realizada por la administración en forma directa, o indirectamente a través de concessionarios y fue el concepto que sirvió para la construcción del viejo derecho administrativo. La relación com el servicio publico era lo que justificaba la competencia de los tribunales llamados contencioso administrativos, la natureza de contrato administrativo que asumían ciertos convenios com la administración, el régimen jurídico del dominio publico, la monopolización del servicio o falta de libre competência, etc... Posteriormente la noción fue perdiendo importancia hasta quedar restringida a mostrar un régimen jurídico especial en determinado tipo de actividad; pero como este régimen jurídico es contingente a politicas económicas que han sido cambiantes em siglo XX, la noción también debe mutar, desaparecer o reaparecer según como se presente esse régimen jurídico en cada contexto económico temporal.

Assim, nota-se que a finalidade para a qual foi desenvolvido o conceito de serviço público na doutrina francesa não existe no Brasil, que não adotou o sistema do contencioso administrativo.

\subsection{Direito americano e as public utilities}

O direito americano não conhece o conceito francês de serviço público. Lá, o conceito mais próximo de serviço público é o das utilidades públicas (public utilities doctrine).

$\mathrm{Na}$ verdade, as utilidades públicas nada mais são do que atividades privadas em que: i) restar identificado um interesse público; ii) existir um dever de provimento universal e em condições equitativas; iii) estarem ligadas a uma dependência de um processo de transporte e distribuição; iv) essas atividades devem estar em larga medida alheias à regra da ampla concorrência por se tratar de monopólio natural ou de direitos exclusivos protegidos pelo Poder Público ${ }^{23}$.

O particular que exerce uma atividade considerada como public utilities fica submetido à obrigação de servir, a continuidade do serviço, a prestá-lo com igualdade de tratamento, portanto, sem discriminação e, se submeter ao dever de realizar uma precificação, deve ser razoável, sem abusos, podendo sofrer restrições impostas pelo Estado tanto em relação às condições de prestação do serviço quanto aos preços cobrados dos particulares ${ }^{24}$. O conceito de utilidade pública do direito americano pode ser ilustrado com o caso Smyth v. Ames 169 U.S. $466(1898)^{25}$ :

A corporation maintaining a public highway, although it owns the property it employs for accomplishing public objects, must be held to have accepted its rights, privileges and franchises subject to the condition that the government creating it, or the government within whose limits it conducts its business, may by legislation protect the people against the exaction of unreasonable charges for the services rendered by it, but it is equally true that the corporation performing such public services, and the people financially interested in its business and affairs, have rights that may not be invaded by legislative enactment in disregard of the fundamental guarantees for the protection of property.

The basis of all calculations as to the reasonableness of rates to be charged by a corporation maintaining

22 GORDILLO, Agustín. Tratado de Derecho Administrativo. 5. ed. Belo Horizonte: Del Rey e Fundación de Derecho Administrativo, 2003. Tomo 2. p. VI-1/2.

23 MARQUES NETO, Floriano de Azevedo. Evolução do Serviço Público. In: KLEIN, Aline Lícia; MARQUES NETO, Floriano de Azevedo. Tratado de Direito Administrativo: funções administrativas do Estado. Coordenação: Maria Sylvia Zanella Di Pietro. São Paulo: Revista dos Tribunais, 2014. p. 31-87. v. 4.

24 Cf. MARQUES NETO, Floriano de Azevedo. Evolução do Serviço Público. In: KLEIN, Aline Lícia; MARQUES NETO, Floriano de Azevedo. Tratado de Direito Administrativo: funções administrativas do Estado. Coordenação: Maria Sylvia Zanella Di Pietro. São Paulo: Revista dos Tribunais, 2014. p. 31-87. v. 4.

25 APPEALS from the circuit court of the united states for the district of Nebraska. Disponível em: <https://supreme.justia.com/cases/ federal/us/169/466/case.html>. Acesso em: 17 dez. 2016. 
a highway under legislative sanction must be the fair value of the property being used by it for the convenience of the public, and in order to ascertain that value, the original cost of construction, the amount expended in permanent improvements, the amount and market value of its bonds and stock, the present as compared with the original cost of construction, the probable earning capacity of the property under particular rates prescribed by statute, and the sum required to meet operating expenses, are all matters for consideration, and are to be given such weight as maybe just and right in each case. What the company is entitled to ask is a fair return upon the value of that which it employs for the public convenience, and on the other hand, what the public is entitled to demand is that no more be exacted from it for the use of a public highway than the services rendered by it are reasonably worth ${ }^{26}$.

Tal conceito serviu de inspiração ao conceito de serviços econômicos de interesse geral.

\subsection{Os serviços econômicos de interesse geral (União Europeia)}

Na Comunidade Europeia, o conceito de serviço público foi substituído pelo de serviços econômicos de interesse geral. Estes se caracterizam por serem atividades privadas que interessam à coletividade, exercidos em um ambiente de concorrência de mercado, conforme disciplina do art. 86.2 do Tratado da Comunidade Europeia:

Empresas encarregadas da operação de serviços de interesse econômico geral ou que tenham a característica de monopólio fiscal, devem sujeitar-se às regras do presente Tratado, em particular regras sobre concorrência, na medida em que a aplicação de tais regras não constitua obstáculo à realização de direito ou de fato da missão particular que lhes tenha sido conferida.

Nota-se que o conceito de serviço público constante do art. 86.2 do Tratado da Comunidade Europeia é muito diferente do encontrado na nossa Constituição Federal que prevê o serviço público como uma atividade prestada pelo Estado diretamente, mediante concessão a particulares ou prestado pelo Estado e pela iniciativa privada, como nos casos de saúde e educação. O denominado serviço de interesse econômico geral nada mais é do que uma atividade livremente exercida por particulares, mas que, diante do interesse público, pode ser disciplinada pelo Estado. O surgimento do conceito de serviço público contido no art. 86.2 do Tratado da Comunidade Europeia decorre da ascensão do ideal neoliberal que predominou na Europa nos anos 80. Nesse sentido é a lição de Aguillar ${ }^{27}$ :

O debate sobre os serviços públicos ressurgiu na Comunidade Europeia por força da revitalização do liberalismo econômico nos anos 1980. Em 1985, foi publicado pela então Comunidade Europeia o Livro Branco sobre o Mercado Interior, pugnando pela liberalização dos serviços públicos. Resgatou-se a interpretação do referido art. 86 (ex-art. 90) do Tratado da Comunidade Europeia e do art. 31 (ex-art. 37), do mesmo tratado que dispõe sobre monopólios comerciais. O art. 31 do TCE determinava que os monopólios devem se ajustar às regras de liberdade e de proibição de discriminação. Note-se que o art. 86 do TCE era constituído de duas partes principais. Na primeira, estabelece-se uma regra geral de que a livre concorrência deve ser estendida a todas as atividades, públicas ou privadas. Na segunda parte, essa regra geral é atenuada pela introdução de uma condição, a de que 'não constitua obstáculo à realização de direito ou de fato da missão particular' que tenha sido confiada aos agentes econômicos estatais ou com privilégios estatais.

\footnotetext{
26 Tradução livre: Uma empresa que mantenha uma ferrovia, embora seja proprietária dos bens que emprega para realizar a atividade de interesse público, deve ser considerada como tendo aceitado seus direitos, privilégios e franquias sujeitos à condição de que o governo pode por lei proteger as pessoas contra a imposição de encargos excessivos pelos serviços prestados, apesar de ser igualmente verdadeiro que a empresa e as pessoas financeiramente interessadas têm direitos que não podem ser desconsiderados pela lei, devido às garantias fundamentais que protegem a propriedade.

A base de todos os cálculos quanto à razoabilidade das taxas a serem cobradas por uma empresa que mantém uma ferrovia, sob pena de sanção legislativa, deve ser o valor justo do imóvel que está sendo usado por ele para a conveniência do público, o custo original de construção, o montante gasto em melhorias permanentes, o valor de mercado de suas obrigações e ações, o presente em comparação com o custo original de construção, a provável capacidade de ganho do imóvel em determinadas taxas prescritas por lei, e o montante necessário para atender às despesas operacionais. O que a empresa tem direito a pedir é um justo retorno sobre o valor daquilo que emprega para atividade de interesse público, e, por outro lado, o que o público tem direito a exigir é que não seja exigido dele mais do que razoavelmente vale os serviços prestados para o uso de uma ferrovia.

${ }_{27}$ AGUILLAR, Fernando Herren. Direito Econômico: do Direito Nacional ao Direito Supranacional. São Paulo: Atlas, 2016. p. 394.
} 
Após os anos 80, na Europa, houve um forte movimento de passagem para a iniciativa privada de serviços antes realizados pelo Estado. E, para fomentar uma regulação indireta, pelo regime de competição de mercado, não existe a denominada concessão de serviços públicos; o serviço de interesse econômico geral pode ser exercido por qualquer particular, sob regime de competição. Existem atividades privadas, consideradas de interesse público, que são reguladas pelo Estado, podendo este, inclusive, impor deveres aos particulares em razão do interesse público ${ }^{28}$. Sobre os serviços públicos de interesse geral, e como estes substituíram os serviços públicos tradicionais na Europa, assim se manifesta Troncoso Reigada ${ }^{29}$ :

Los servicios públicos tradicionales se han visto afectados por el Derecho comunitario que há establecido como regla general la liberalización de la economía — la depublicatio — y el sometimiento de la actividad económica al Derecho de la competencia. Han aparecido así unos servicios de interés económico general que se caracterizan —y se diferencian de los servicios públicos tradicionales- porque la actividad no es de titularidad pública sino que es ejercida por los particulares en régimen de libertad y que la prestación de interés general no es desarrollada por los poderes públicos sino por los particulares. Por tanto, la regla general es que esta actividad considerada de interés general sea desarrollada libremente en el mercado. Ahora bien, cuando esta actividad no va a ser cubierta por el empresario atendiendo a su propio interés comercial, los poderes públicos podrán imponer a las empresas obligaciones de servicio universal, que se desarrollarán también en régimen de libre competencia, aunque con una mayor intensidad de regulación. Sólo en última instancia se recurre al régimen de exclusiva —y a la supresión de la competencia - para garantizar las prestaciones vitales necesarias. Es decir, sólo se suprime el derecho de la competencia cuando ésta impida de hecho o de derecho la actividad de interés general artículo 86.2 TCE- De esta forma, la práctica totalidad de los servicios públicos tradicionales han sido despublificados a partir de distintas Leyes y normas comunitarias y han sido sustituidos por servicios de interés económico general, lo que evita el riesgo de que la renuncia a los servicios públicos deje abandonadas zonas o capas sociales donde los servicios no sean rentables en un régimen de mercado. En ese caso, la llamada «garantía pública» del servicio sólo se extiende a la regulación y al control externo de la actividad por parte de los poderes públicos. Los servicios de interés general no son iniciativas públicas — sólo excepcionalmente los prestan empresas públicas—, a menos que se califique como tal las obligaciones impuestas a los particulares. Se tendría que hablar mejor de servicios con garantía social. Los particulares van a desarrollar estos servicios — porque se piensa que lo hacen mejor- y los poderes públicos cumplen su función propia, que es ordenarlos y supervisarlos, y, en casos puntuales, financiarlos.

Inspirado no conceito de serviço econômico de interesse geral, já existe entendimento no Brasil de que o serviço público seria somente um instrumento para a realização dos direitos fundamentais, razão pela qual não poderia ser sujeito a um único regime jurídico, como o da concessão e permissão ${ }^{30}$. Deveria haver um regime de livre competição, com a possibilidade de qualquer interessado realizar o serviço público ${ }^{31}$, que

\footnotetext{
28 "É fato que para a noção tradicional de serviços públicos será fortemente impactada pela introdução do conceito de serviços de interesse econômico geral. Desde agora importa destacar que o resultado desta nova concepção europeia de serviço público (impactada pela necessidade de observância das regras da concorrência no mercado comum europeu) foi a crescente liberalização e privatização de empresas estatais prestadoras dos serviços públicos tradicionais. A liberalização implicou a abertura ao mercado de setores submetidos a monopólios públicos, franqueando aos particulares atuar na oferta desses serviços, com todos os desafios inerentes ao regime de liberdade de mercado". MARQUES NETO, Floriano de Azevedo. Evolução do Serviço Público. In: KLEIN, Aline Lícia; MARQUES NETO, Floriano de Azevedo. Tratado de Direito Administrativo: funções administrativas do Estado. Coordenação: Maria Sylvia Zanella Di Pietro. São Paulo: Revista dos Tribunais, 2014. p. 31-87. v. 4.

29 TRONCOSO REIGADA, Antônio. Dogmática Administrativa y Derecho Constitucional: em caso del servicio público. Revista Española de Derecho Constitucional, año 19. n. 57, p. 87-164. Sep./Dic. 1999.

30 Nesse sentido: "O serviço público nada mais é do que um instrumento para a realização dos direitos fundamentais, em função dos quais não se pode mais ser considerado como prerrogativa estatal que desautoriza, em qualquer circunstância, o exercício da atividade por particulares - as quais muita podem prestá-lo com maior eficiência -, tampouco pode ficar sujeito a um único regime jurídico, eis que as atividades são muito distintas para serem submetidas ao mesmo regime". MARQUES NETO, Floriano de Azevedo. Evolução do Serviço Público. In: KLEIN, Aline Lícia; MARQUES NETO, Floriano de Azevedo. Tratado de Direito Administrativo: funções administrativas do Estado. Coordenação: Maria Sylvia Zanella Di Pietro. São Paulo: Revista dos Tribunais, 2014. p. 89-113. v. 4.

31 Nesse sentido: "A nosso ver, contudo, a incumbência de prestação referida pelo texto Constitucional possui um sentido que se afasta da noção de exclusividade ou de prerrogativa do Estado, para a noção dever estatal de garantir a prestação, seja direta ou indiretamente, seja ainda mediante a abertura da atividade à exploração pelos agentes privados, desde que assegurados os princípios
} 
deveria ter, somente, a regulação estata ${ }^{32}$. O Estado somente deveria atuar de forma secundária, cabendo à iniciativa privada a prestação do serviço público. Nesse sentido é o entendimento de Floriano de Azevedo Marques Neto:

Por isso é que, embora à primeira vista o art. 173 da CF/1988 pareça se referir apenas á atuação do Estado em regime de concorrência, ficando excluída da regra da subsidiariedade a prestação dos serviços públicos, a nova dimensão assumida pelos serviços públicos no contexto atual (serviço de interesse econômico geral), somada ao reconhecimento de que os serviços públicos nada mais são do que atividades econômicas sujeitas à maior intensidade da regulação estatal ? devido à obrigação do Estado em fornecêlas aos cidadãos -, evidenciam que também nos casos de atividades consideradas "serviços públicos" o Estado deve atuar apenas em caráter subsidiário, sempre quando a atuação dos particulares for insuficiente ou prejudicial à universalização e continuidade do provimento da utilidade pública à coletividade ${ }^{33}$.

Entretanto, salvo melhor juízo, não se torna possível trazer a disciplina dos serviços econômicos de interesse geral da Europa para substituir a noção de serviço público. A disciplina da União Europeia é totalmente incompatível com a atual disciplina da Constituição Federal, tendo em vista que o disposto no art. 175 da Constituição Federal impõe que o serviço público deve ser prestado pelo Estado ou por particulares, em regra de forma monopolista, por meio do contrato de permissão ou concessão de serviço público.

\section{Conceito de serviço público no Brasil}

O conceito de serviço público tem que ser formulado com fulcro no direito positivo constitucional brasileiro. O conceito de serviço econômico de interesse geral não se coaduna com o sistema positivado pela Constituição Federal de 1988. Dessa forma, não cabe falar em fim do serviço público. Nesse sentido é a lição de Celso Antônio Bandeira de Mello ${ }^{34}$ :

O serviço público constitui-se em uma das mais importantes noções do direito administrativo brasileiro, porque tem assento constitucional especificador de um vasto campo de deveres do Estado brasileiro em relação à Sociedade, sobre se constituir em fundamento da cobrança de relevante variedade de taxas. Diante da orquestrada zoeira da privatização, em diferentes partes do mundo, mas sobre-posse entre os sub ou semidesenvolvidos (como é natural) e até mesmo no Brasil - em despeito dos dizeres da Constituição -, chegou-se a apregoar o fim da noção de serviço público e uma suposta superação do Direito Administrativo até então existente, substituídos um e outro pelas maravilhas da livre iniciativa e da atoregulação do mercado, tudo no melhor estilo e sotaque norte-americano.

A Constituição Federal nos deu uma noção de serviço público ${ }^{35}$ que abrange: i) os elencados na Cons-

que informam a prestação dos serviços e regulam o seu oferecimento ao público (regulação estatal, política tarifária, direitos dos usuários, universalidade, continuidade, isonomia, qualidade etc)". MARQUES NETO, Floriano de Azevedo. Evolução do Serviço Público. In: KLEIN, Aline Lícia; MARQUES NETO, Floriano de Azevedo. Tratado de Direito Administrativo: funções administrativas do Estado. Coordenação: Maria Sylvia Zanella Di Pietro. São Paulo: Revista dos Tribunais, 2014. p. 89-113. v. 4.

32 Nesse sentido: "A introdução da competição e a convivência de operadores econômicos privados na atividade de prestação de serviços públicos liberalizados trazem consigo a necessidade de uma verdadeira reformulação da teoria do serviço público tradicional, na medida em que muitos dos seus pressupostos - como a exclusividade estatal da prestação, a unicidade de regime jurídico e as prerrogativas estatais - são agora esvaziados diante da revisão da noção e abrangência de serviço público na atualidade". MARQUES NETO, Floriano de Azevedo. Evolução do Serviço Público. In: KLEIN, Aline Lícia; MARQUES NETO, Floriano de Azevedo. Tratado de Direito Administrativo: funções administrativas do Estado. Coordenação: Maria Sylvia Zanella Di Pietro. São Paulo: Revista dos Tribunais, 2014. p. 89-113. v. 4.

33 MARQUES NETO, Floriano de Azevedo. Evolução do Serviço Público. In: KLEIN, Aline Lícia; MARQUES NETO, Floriano de Azevedo. Tratado de Direito Administrativo: funções administrativas do Estado. Coordenação: Maria Sylvia Zanella Di Pietro. São Paulo: Revista dos Tribunais, 2014. p. 89-113. v. 4.

34 MELLO, Celso Antônio Bandeira de. Curso de Direito Administrativo. 27. ed. São Paulo: Malheiros, 2010. p. 673, nota de rodapé 5. 35 Sobre o conceito de serviço público: "Serviço público é toda atividade exercida pelo Estado ou por quem lhe faça as vezes, para a realização direta ou indireta de suas finalidades e das necessidades ou comodidades da coletividade, ou mesmo conveniências do Estado, tudo conforme definido pelo ordenamento jurídico, sob o regime peculiar, total ou parcialmente público, por ele imposto”. ARAÚJO, Edmir Netto de. Curso de Direito Administrativo. 5. ed. São Paulo: Saraiva, 2010. p. 128. 
tituição Federal que somente podem ser objeto de prestação direta pelo Estado ou de forma indireta por este, mediante a concessão e permissão de serviço público ${ }^{36}$; ii) abrange também as prestações de utilidade pública que podem ser realizadas, de forma complementar, pela iniciativa privada, como saúde e educação; iii) os não expressamente elencados na Constituição Federal ${ }^{37}$, mas que se tornem um dever do Estado, em razão da necessidade de efetivação dos direitos fundamentais.

O rol dos serviços públicos não é fixo, sendo alterado de acordo com as necessidades coletivas, sempre por uma escolha política, amparada em lei. Uma atividade que hoje não é serviço público pode ser transformada em serviço público, desde que necessária ao atendimento do interesse público e efetividade dos direitos fundamentais. Da mesma forma, uma atividade que hoje é considerada um serviço público pode deixar de sê-lo, desde que desnecessária a atuação estatal. Nesse sentido, ainda é atual a lição de Gaston Jezé38:

Finalmente, el procedimento del servicio público no se usa em todas las épocas para uma misma necesidad. Hay necesidades para cuya satisfacción se há abandonado el procedimiento del servicio público, luego de habérselo seguido (cultos); a la inversa, existen otras para las que se recurre em la actualidad a este procedimiento, no habiéndoselo utilizado anteriormente (teatros nacionales).

Os serviços públicos podem sem instituídos por lei, sem necessidade de emenda constitucional ${ }^{39}$. O Estado não é livre para declarar qualquer atividade como serviço público ${ }^{40}$. Porém, havendo a necessidade de fomentar a efetividade de qualquer direito fundamental, pode e deve o Estado, por lei, declarar qualquer atividade como serviço público, inclusive as atividades de natureza econômica, conforme previsto no art. 173 da Constituição Federal ${ }^{41}$.

\footnotetext{
36 Nesse sentido: "Assim, no Brasil, os serviços públicos, bem como as respectivas competências para prestá-los, estão todos expressos como funções administrativas na Constituição de 1988, seja explicitamente, como nos arts. 21, 35, 30 e dispositivos extravagantes dos arts. 194, 196, 200, 201, 203, 205, 208, 211 e 223, seja implicitamente, como os que sejam deles derivado e, ainda, todos os demais, que necessitem ser prestados em regime de exploração de atividade econômica". MOREIRA NETO, Diogo de Figueiredo. Curso de Direito Administrativo. 15. ed. Rio de Janeiro: Forense, 2009. p. 474.

37 Sobre a possibilidade de criar serviços públicos não expressos na Constituição Federal: "Por outro lado, não se pode reputar que todos os possíveis serviços públicos teriam sido referidos exaustivamente na dimensão constitucional...Excluídos dois campos $3 / 4$ aquilo que é obrigatoriamente serviço público e aquilo que não pode ser serviço público 3/4, existe a possibilidade de o legislador infraconstitucional determinar outras atividades como tais, respeitados os princípios constitucionais". JUSTEN FILHO, Marçal. Curso de Direito Administrativo. 8. ed. Belo Horizonte: Fórum, 2012. p. 697.

38 JEZÉ, Gaston. Principios generales del Derecho Administrativo. Traducion por Julio N. San Millán Almagro. Buenos Aires: Depalma, 1949. p. 24.

39 Nesse sentido: "Em suma, cabe à lei ordinária determinar a publicização de certa atividade e as hipóteses em que configurará serviço público. Isso não equivale a reconhecer uma autonomia ilimitada para o legislador ordinário. Não é indiferente para a Constituição que as atividades referidas nos incisos X a XII do art. 21 sejam tratadas como serviço público ou como atividade econômica em sentido estrito. Tese dessa ordem é indefensável e infringe os artigos 170, 173 e 175 da CF/88”. JUSTEN FILHO, Marçal. Curso de Direito Administrativo. 8. ed. Belo Horizonte: Fórum, 2012. p. 696.

40 Sobre os limites para a criação de serviços públicos: "Segundo a tese ora adotada, a configuração de atividades como serviço público faz-se essencialmente a partir do critério da referibilidade direta e imediata aos direitos fundamentais. Algumas utilidades apresentam intensa pertinência a tanto, motivo pelo qual foram referidas constitucionalmente. Isso não significa que a Constituição teria transformado como serviço público toda e qualquer atuação relacionada a tais atividades. Sempre se impõe como indispensável a vinculação com os direitos fundamentais". JUSTEN FILHO, Marçal. Curso de Direito Administrativo. 8. ed. Belo Horizonte: Fórum, 2012. p. 697.

${ }^{41}$ Ou seja, uma atividade econômica pode, se existir relevante interesse coletivo ou motivos de segurança nacional, ser transformada em serviço público. Nesse sentido: "Neste último caso, de ser necessário, para instituir e prestar um serviço público, realizar-se algum tipo de exploração de atividade econômica, que está, por princípio, reservada à sociedade, a Constituição, além dos casos expressamente nela previstos, permite que o legislador o institua nas duas restritas hipóteses previstas no art. 173, por isso mesmo, admitidas como exceção no seu Título VII, que versa sobre a Ordem Econômica e Financeira, ou seja: desde que necessárias aos imperativos da segurança nacional ou ao atendimento de relevante interesse coletivo". MOREIRA NETO, Diogo de Figueiredo. Curso de Direito Administrativo. 15. ed. Rio de Janeiro: Forense, 2009. p. 474.
} 


\section{Considerações finais}

O serviço público é uma atividade econômica prevista na Constituição Federal como passível de ser prestada pelo Estado. Não mais faz sentido as tentativas de apartar o conceito de serviço público e atividade econômica. O serviço público é uma atividade econômica prestada pelo Estado diretamente ou por meio de concessão, em regra de forma monopolista, salvo os serviços de educação e saúde.

Os institutos do Direito Europeu e Estadunidense de "serviços econômicos de interesse geral e "public utilities" não são totalmente adequados ao conceito de serviço público positivado na Constituição Federal. Tais institutos mais se aproximam de atividades privadas onde exista um interesse público em regular e limitar tais atividades, não se confundindo com o interesse público.

O serviço público deve ser focado mais no seu caráter instrumental, como meio para o Estado promover os direitos sociais, razão pela qual é possível que a lei opte por transformar qualquer atividade econômica em serviço público.

\section{Referências}

AGUILLAR, Fernando Herren. Direito Econômico: do Direito Nacional ao Direito Supranacional. São Paulo: Atlas, 2016.

ARAÚJO, Edmir Netto de. Curso de Direito Administrativo. 5. ed. São Paulo: Saraiva, 2010.

GORDILLO, Agustín. Tratado de Derecho Administrativo. 5. ed. Belo Horizonte: Del Rey e Fundación de Derecho Administrativo, 2003. Tomo 2.

GRAU, Eros. A ordem econômica na Constituição de 1988. 17. ed. São Paulo: Malheiros, 2015.

JEZÉ, Gaston. Principios generales del Derecho Administrativo. Traducion por Julio N. San Millán Almagro. Buenos Aires: Depalma, 1949.

JUSTEN FILHO, Marçal. Contornos da atividade administrativa de fomento no direito administrativo brasileiro: novas tendências. In: MELLO, Celso Antônio Bandeira de et al. Direito Administrativo e Liberdade: Estudos em homenagem a Lúcia Valle Figueiredo. São Paulo: Malheiros, 2014. p. 536-566.

JUSTEN FILHO, Marçal. Curso de Direito Administrativo. 8. ed. Belo Horizonte: Fórum, 2012.

LOUREIRO, Luiz Gustavo Kaercher. Premissas para uma leitura integrada da indústria de energia na Constituição e para a identificação de uma política energética constitucional - a propósito dos arts. 173 e 175 da Carta. In: ARAGÃO, Alexandre Santos de. Direito do petróleo e de outras fontes de energia. Rio de Janeiro: Lumen Juris, 2011. p. 303-325.

MARQUES NETO, Floriano de Azevedo. Evolução do Serviço Público. In: KLEIN, Aline lícia; MARQUES NETO, Floriano de Azevedo. Tratado de Direito Administrativo: funções administrativas do Estado. Coordenação: Maria Sylvia Zanella Di Pietro. São Paulo: Revista dos Tribunais, 2014. p. 31-87. v. 4.

MELLO, Celso Antônio Bandeira de. Curso de Direito Administrativo. 27. ed. São Paulo: Malheiros, 2010.

MOREIRA NETO, Diogo de Figueiredo. Curso de Direito Administrativo. 15. ed. Rio de Janeiro: Forense, 2009 .

RIVERO, Jean. Direito administrativo. Tradução Rogério Ehrhardt Soares. Coimbra: Almedina, 1981.

TRONCOSO REIGADA, Antônio. Dogmática Administrativa y Derecho Constitucional: em caso del servicio público. Revista Española de Derecho Constitucional, año 19. n. 57, p. 87-164. Sep./Dic. 1999. 
Para publicar na revista Brasileira de Políticas Públicas, acesse o endereço eletrônico www.rbpp.uniceub.br

Observe as normas de publicação, para facilitar e agilizar o trabalho de edição. 